\title{
Una reseña sobre el libro “Guía práctica de pragmática del español"
}

\author{
A review of "Practical Guide to Pragmatics of Spanish" \\ Carlos Álvarez \\ Departamento de Fonoaudiología - Universidad de Chile \\ Grupo de investigación Koiné - Universidad de Santiago de Compostela
}

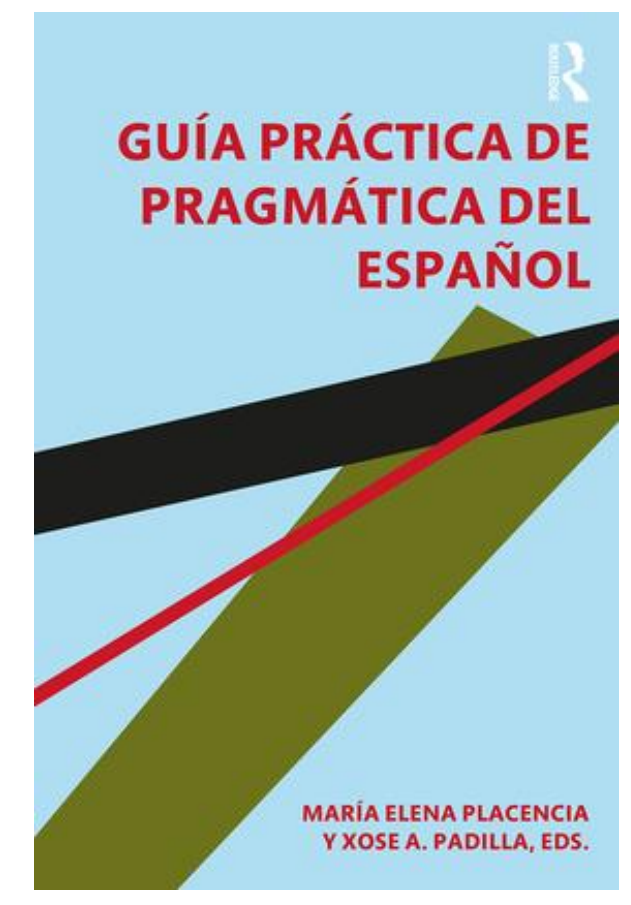

Editores: María Elena Placencia y Xose A. Padilla

Editorial: Routledge

Número de páginas: 280 páginas

Año: 2019

ISBN: 978-0-8153-5770-4 


\section{La esencia invisible en la comunicación humana}

Resulta siempre ser una buena noticia la publicación de una obra acerca de uno de los ámbitos más atractivos y recónditos de todo acto comunicativo-lingüístico humano: la pragmática. La noticia se torna aún mejor si se considera que la obra trata de la pragmática de una de las lenguas más habladas en el mundo: el español. Así, Guía Práctica de Pragmática del Español, de la editorial británica Routledge, representa una importante contribución al conocimiento de la pragmática de la lengua española que por décadas se ha edificado a partir de trabajos de hispanistas como Henk Haverkate, Antonio Briz, Graciela Reyes, José Portolés, María Victoria Escandell, entre otras y otros.

Los editores de Guía Práctica de Pragmática del Español, María Elena Placencia y Xose Padilla, cuentan con una destacada trayectoria en investigación y docencia en el ámbito de la pragmática, en general, y de aspectos específicos como ironía, variación pragmática, fonopragmática, el acto de habla del cumplido, en particular. Del mismo modo, cada uno de los autores de los capítulos que componen esta obra entrega al lector el conocimiento teórico y herramientas prácticas que le permiten desarrollar habilidades de análisis pragmático de interacciones en español en contextos cotidianos de uso. El análisis pragmático es una herramienta ampliamente utilizada en diversos ámbitos profesionales y académicos. En este sentido, esta habilidad reviste significativa relevancia en la práctica fonoaudiológica clínico-educativa: la evaluación de las capacidades de comunicación y lenguaje en un individuo no puede excluir el análisis de los principios que orientan el uso del lenguaje en actos comunicativos. Amplia evidencia científica da cuenta de la desfavorable incidencia que tienen ciertos síndromes y trastornos en las capacidades pragmáticas. Por tanto, en el ámbito fonoaudiológico, un exhaustivo análisis pragmático resulta ineludible e imprescindible. De ahí que Guía Práctica de Pragmática del Español constituye un valioso material de consulta que ofrece al lector, con un favorable balance teórico-práctico, un panorama de los aspectos más relevantes de la pragmática moderna.

La obra se organiza en veintidós capítulos distribuidos en seis secciones. La primera de estas secciones da cuenta de una de las teorías que, trascendiendo décadas, aún se considera un pilar fundamental de la pragmática moderna: la teoría de los actos de habla. En esta primera sección, los actos de habla 
abordados son: pedidos, rechazos, cumplidos, consejos en los foros digitales y disculpas. La segunda sección, Deixis social, consta de dos capítulos en los que se tratan los siguientes temas: tratamiento pronominal y los vocativos. La tercera sección, La (des)cortesía, cuenta con seis capítulos, entre los que destacan aquellos relacionados con el fenómeno de la comunicación mediada por dispositivos tecnológicos: La descortesía en redes sociales y Emoticonos y emojis: su relación con la cortesía en la comunicación digital. La cuarta sección, Comunicación y persuasión, cuenta con seis capítulos: Humor y comunicación multimodal: las viñetas cómicas, Argumentación y discurso político, La serie enumerativa como elemento intensificador en el discurso político, Marcadores de discurso y argumentación, Persuasión emocional, argumentación y publicidad y Comunicación no verbal. La quinta sección, titulada El discurso digital, cuenta con dos capítulos: La construcción de la identidad en las redes sociales y La comunicación en línea: aspectos tecnológicos, sociales y situacionales. Finalmente, la sexta sección, Metodología en el estudio de la pragmática, contiene un capítulo titulado Pautas para la elaboración de un proyecto de investigación en pragmática.

En relación con los capítulos de la obra, es posible establecer que la estructura interna que estos poseen facilita la comprensión y permite una lectura fluida y amena de los contenidos. De los apartados que componen cada capítulo, destaca el llamado Análisis, en el cual cada autor guía el proceso de aplicación del conocimiento teórico previamente tratado en una amplia variedad de actividades prácticas. Estas incluyen análisis de transcripciones de muestras conversacionales presenciales, análisis de actos comunicativos en redes sociales, análisis de interacciones en la cuales el lector debe participar como interlocutor, por nombrar algunas. Estas actividades de análisis brindan, especialmente a lectores del campo fonoaudiológico, una valiosa instancia de práctica orientada al desarrollo de habilidades de análisis pragmático de situaciones comunicativas con un alto grado de espontaneidad. El desarrollo de esta habilidad permite a fonoaudiólogas y fonoaudiólogos poder complementar y enriquecer las caracterizaciones comunicativo-lingüísticas comúnmente obtenidas mediante la aplicación de pruebas estandarizadas en la cuales, por su naturaleza, la espontaneidad resulta mermada. Un segundo apartado a destacar es Posibles temas para un ensayo o proyecto del curso. Este apartado, como su título lo explicita, entrega al lector interesantes ideas a desarrollar 
en formato ensayo o proyecto de investigación. Por tanto, este apartado es sumamente sugestivo y uno de los sellos prácticos de la obra.

Cada uno de los capítulos dota al lector de información actualizada acerca de la pragmática moderna. Cabe destacar la presencia de capítulos cuyas temáticas no siempre tiene cabida en los tratados de pragmática. Acerca de este último punto, es especialmente atractivo la presencia del capítulo titulado Comunicación no verbal, el cual da cuenta de manera lúcida de las complejidades propias de la comunicación humana y como esta se realiza mediante sistemas lingüísticos y no lingüísticos. De manera acertada, la autora del capítulo, Ana Cestero Mancera, inicia el capítulo aseverando que un gesto vale más que mil palabras. No podría estar más de acuerdo con la autora al darme cuenta de que, al momento de leer dicha aseveración, asiento con mi cabeza por algunos segundos. Un valioso capítulo que, junto con aquellos que dan cuenta de la pragmática en contextos comunicativos mediados por dispositivos tecnológicos, le otorgan una favorable frescura a la obra.

Los aspectos antes mencionados motivan a recomendar la lectura de Guía Práctica de Pragmática del Español. En esta obra, estudiantes de Fonoaudiología y profesionales Fonoaudiólogas y Fonoaudiólogos encontrarán una valiosa fuente de información acerca de un importante número de temáticas relevantes del ámbito de la pragmática del español. Como su nombre lo establece, la obra es una guía práctica con recursos que sin duda pueden ser utilizados en la práctica fonoaudiológica clínico-educativa. Así, Guía Práctica de Pragmática del Español visibiliza claramente la esencia invisible en la comunicación humana. Indudablemente recomendable. 